\title{
Microaggressions, diabetes distress, and self-care behaviors in a sample of American Indian adults with type 2 diabetes
}

\author{
Kelley J. Sittner ${ }^{1} \cdot$ Brenna L. Greenfield $^{2} \cdot$ Melissa L. Walls ${ }^{2}$
}

Received: March 26, 2017 / Accepted: October 30, 2017 /Published online: November 7, 2017

(C) Springer Science+Business Media, LLC 2017

\begin{abstract}
American Indian/Alaska Native people experience the highest age-adjusted prevalence of type 2 diabetes of any racial group in the United States, as well as high rates of related health problems. Chronic stressors such as perceived discrimination are important contributors to these persistent health disparities. The current study used structural equation modeling to examine the relationships between racial microaggressions, diabetes distress, and self-care behaviors (diet and exercise) in a sample of 192 American Indians with type 2 diabetes from the northern United States. We found that microaggressions was positively associated with diabetes distress and that microaggressions had an indirect link to self-care via diabetes distress. Diabetes distress is an important mechanism linking microaggressions to self-care behaviors, which are critical to successful disease management and the reduction of complications. The amelioration of diabetes distress could improve self-care even in the presence of pervasive, chronic social stressors such as microaggressions.
\end{abstract}

Keywords Diabetes · Microaggressions · Diabetes distress · Stress · American Indian

Kelley J. Sittner

kelley.sittner@okstate.edu

1 Department of Sociology, Oklahoma State University, 431 Murray Hall, Stillwater, OK 74078, USA

2 Department of Biobehavioral Health and Population Sciences, University of Minnesota Medical School, Duluth Campus, 1035 University Drive, Duluth, MN 55812, USA

\section{Introduction}

American Indian/Alaska Native people experience the highest age-adjusted prevalence of type 2 diabetes (hereafter diabetes) of any racial group in the United States, and disparately high prevalence of related health problems, including coronary heart disease, kidney disease, and hypertension (Blackwell et al., 2014). Compared to the general U.S. population, American Indian (AI) people live on average 4.4 fewer years (Indian Health Service, 2016), with more years of life lost due to diabetes (National Center for Health Statistics, 2016). Differential exposure to stress is one contributor to increased rates of diabetes and related complications among AI people. Stress process theories explicitly connect exposure to stressors to worse mental and physical health outcomes (Pearlin et al., 1981; Walters \& Simoni, 2002). Further, stressors negatively impact health behaviors and have been associated with poorer glycemic control, obesity, and insulin resistance for patients with diabetes (Aikens \& Mayes, 1997; Jiang et al., 2008). This study considers whether the relationship between racial discrimination and poorer diabetes self-care may be driven by diabetes-related distress in a sample of AIs with diabetes.

\section{Racial discrimination and health behaviors}

Marginalized groups experience a disproportionate number of stressors (Turner et al., 1995), which contribute to greater disease burden (Pearlin et al., 1981). Chronic stressors such as racial discrimination, due to their recurring and prolonged character (Pearlin et al., 2005), are particularly detrimental to health. They are important antecedents to many persistent physical and mental health disparities for racial and ethnic minority groups (Pascoe \& 
Smart Richman, 2009; Williams \& Mohammed, 2009). For example, racial discrimination has been associated with both preclinical markers of poor health (e.g., shorter telomere length) and clinical endpoints such as ambulatory blood pressure levels and all-cause mortality (Brondolo et al., 2011; Dolezsar et al., 2014; Lewis et al., 2015). Discrimination and Health Behaviors Most research on racial discrimination and health among North American Indigenous people has utilized measures of more overt forms of interpersonal discrimination, finding relationships between discrimination and elevated suicide rates, mental health problems, and prevalence of type 2 diabetes (Jiang et al., 2008; McQuaid et al., 2015; Walls et al., 2007).

Microaggressions, a subcategory of racial discrimination that includes everyday slights, insults, and prejudices (Sue et al., 2007), reflect a subtle, covert form of racism. Microaggressions are also consequential for health, including diabetes-related health problems. In one of the few studies to date to examine this issue among AI people with diabetes, Walls et al., (2015) found that microaggressions experienced in a healthcare setting were positively associated with depressive symptoms and the prevalence of past-year hospitalizations.

\section{Diabetes distress, racial discrimination, and self- care}

As with other stressors, racism impacts physical health in part through its effect on psychological distress (Paradies, 2006). Depressive symptoms are positively associated with racism (Pascoe \& Smart Richman, 2009; Williams \& Mohammed, 2009) and high prevalence of comorbid diabetes and depression has been found (Anderson et al., 2001). However, it is likely that diabetes-specific distress is also common as the burden of living with and managing a chronic disease can itself cause distress (Fisher et al., 2007; Iwasaki et al., 2005). Diabetes distress is the "unique, often hidden emotional burdens and worries" related to managing a chronic disease such as diabetes (Fisher et al., 2012, p. 259), such as physical limitations, chronic pain management, disease complications, and psychological issues (Iwasaki et al., 2005). Diabetes distress hinders disease management, including glycemic control, medication adherence, and selfcare (Gonzales et al., 2015; Schmitt et al., 2015; Zagarins et al., 2012). Diabetes distress is also related to non-disease specific stressors, including discrimination (Wagner et al., 2013), making diabetes distress a possible mechanism linking discrimination to disease outcomes.

The current study used structural equation modeling to examine the associations among microaggressions, diabetes distress, and self-care behaviors (i.e., diet and exercise) in a sample of AI adults with diabetes. We tested the following three hypotheses: first, microaggressions would be positively related to diabetes distress and negatively related to diet and exercise; second, diabetes distress would be negatively related to self-care behaviors; and third, microaggressions would have an indirect effect on self-care through its relationship with diabetes distress. We also include depressive symptoms to determine whether the relationships among microaggressions, distress, and selfcare are specific to diabetes distress or to more general psychological distress.

\section{Research design and methods}

\section{Study design and procedures}

Data come from the Maawaji' idi-oog Mino-ayaawin (Gathering for Health) study, a longitudinal communitybased participatory study of stress and type 2 diabetes in progress with five reservations in the northern Midwest. Tribal councils approved the project prior to obtaining funding. Community research councils (CRCs) at each location worked in conjunction with university project staff on measurement adaptation, data collection, and analysis. Tribal clinic partners used probability sampling and clinical records to generate random samples of patients at least 18 years old with a type 2 diabetes diagnosis, and selfidentifying as AI. Selected patients were mailed invitation letters with phone and write-in options for refusal. Nonrefusing patients were visited by project interviewers who secured informed consent. In this investigation we use Wave 1 survey data collected via computer assisted personal interviewing (CAPI) between November 2013 and November 2015. Community interviewers underwent intensive training on CAPI techniques and human subjects' protection; this included instructions on adherence to questionnaire wording for standardization across interviews, appropriate use of probes and prompts, and recognizing signs of participant fatigue or distress. Interviews took place in participants' homes or in secure, private locations. Interviewers read each question aloud and entered participant responses directly into field laptops. After each survey, interviewers used Internet connections to securely upload data to University servers. Participants were given a $\$ 50$ mailed check incentive for survey completion. All study procedures and materials were approved by University of Minnesota Institutional Review Board.

\section{Measures}

Microaggressions were measured with 11 items representing experiences with everyday, subtle, and often unconscious biases related to one's cultural group mem- 
bership (adapted from Chae \& Walters, 2009). The specific questions and response options are provided in Table 1. Diabetes distress was adapted from Fisher et al. (2008) and consisted of two items assessing the degree to which respondents were bothered or distressed by their disease. Diet and exercise each consisted of two items adapted from the Summary of Diabetes Self-Care Activities (Toobert et al., 2000). We also included a measure of depressive symptoms to assess the relationship between microag- gressions and depression, as well as the relationship between depression and self-care. Depressive symptoms were measured using the nine-item depression module of the Patient Health Questionnaire, which assesses frequency of symptoms over the past 2 weeks (Kroenke et al., 2001). Four additional control variables were included. Participants self-reported their gender as either male (0) or female (1). Per capita household income was measured by asking respondents to indicate their overall household incomes as

Table 1 Latent variable item means, standard deviations, and factor loadings

Mean $s d$ Factor loading

Microaggressions $^{\mathrm{a}}$

1. Unfair treatment by bosses/supervisors

2. Being called something racist

3. Feeling like Native people are invisible

4. Hearing from non-Natives how surprisingly well-read or smart you are

5. Non-Natives stating you don't look or act Indian

6. Feeling stereotyped by non-Native persons

7. Seeing portrayals of Native people in TV, movies, or as sports mascots

8. Someone suspecting you of doing something wrong because you are Native

9. People acting afraid of you because you are Native

10. People accusing you of being oversensitive when you try to discuss race issues or racism

11. Feeling like you are treated differently

Diabetes distress ${ }^{\mathrm{b}}$

1. Feeling overwhelmed by demands of living with diabetes

2. Feeling like you are often failing with diabetes regimen

Depressive symptoms ${ }^{\mathrm{c}}$

1. Little interest or pleasure in doing things.

2. Feeling down, depressed, or hopeless

3. Feeling bad about yourself or that you are a failure or have let yourself down

4. Feeling tired or having little energy

5. Poor appetite or overeating

6. Trouble falling or staying asleep, or sleeping too much

$\begin{array}{lll}0.28 & 0.63 & 0.334^{\mathrm{e}}\end{array}$

$\begin{array}{lll}0.48 & 0.74 & 0.474\end{array}$

$\begin{array}{llll}0.97 & 0.88 & 0.514\end{array}$

$\begin{array}{lll}0.55 & 0.73 & 0.486\end{array}$

$\begin{array}{llll}0.37 & 0.65 & 0.236^{\mathrm{e}}\end{array}$

$\begin{array}{lll}0.77 & 0.83 & 0.642\end{array}$

$\begin{array}{lll}1.06 & 0.77 & 0.619\end{array}$

$\begin{array}{llll}0.96 & 0.94 & 0.699\end{array}$

$\begin{array}{llll}0.68 & 0.81 & 0.657\end{array}$

$\begin{array}{llll}0.53 & 0.79 & 0.643\end{array}$

$\begin{array}{lll}1.01 & 0.90 & 0.709\end{array}$

$\begin{array}{lll}1.53 & 1.55 & 0.709\end{array}$

$\begin{array}{lll}1.60 & 1.66 & 0.676\end{array}$

$\begin{array}{lll}0.55 & 0.93 & 0.699\end{array}$

$\begin{array}{llll}0.54 & 0.90 & 0.686\end{array}$

$\begin{array}{llll}0.42 & 0.80 & 0.684\end{array}$

$\begin{array}{lll}1.01 & 1.04 & 0.642\end{array}$

$\begin{array}{llll}0.92 & 1.06 & 0.603\end{array}$

$\begin{array}{llll}0.99 & 1.13 & 0.672\end{array}$

$\begin{array}{llll}0.54 & 0.92 & 0.759\end{array}$

7. Trouble concentrating on things, such as reading the newspaper or watching television

$\begin{array}{lll}0.22 & 0.56 & 0.647\end{array}$

8. Moving or speaking so slowly that other people have noticed. Or the opposite-being so fidgety or restless that you 0.22 have been moving around a lot more than usual

9. Thoughts that you would be better off dead, or of hurting yourself in some way

$\begin{array}{lll}0.10 & 0.44 & 0.549\end{array}$

Diet ${ }^{\mathrm{d}}$

1. Follow a healthful eating plan

$\begin{array}{lll}3.09 & 2.42 & 0.606\end{array}$

2. Eat five or more servings of fruits and vegetables in a day

$\begin{array}{lll}2.00 & 2.02 & 0.705\end{array}$

Exercise $^{\mathrm{d}}$

1. Participate in at least $30 \mathrm{~min}$ of physical activity

$\begin{array}{lll}3.69 & 2.22 & 0.698\end{array}$

2. Participate in a specific exercise session

${ }^{a}$ Response options were $0=$ this never happened; $1=$ this happened but it didn't bother me; $2=$ this happened and I was bothered by it ${ }^{\mathrm{b}}$ Response options ranged from $0=$ not at all bothersome to $5=$ very bothersome

${ }^{\mathrm{c}}$ Response options were $0=$ not at all; $1=$ several days; $2=$ more than half the days; $3=$ nearly every day

${ }^{\mathrm{d}}$ Response options were $0-7$ days

${ }^{\mathrm{e}}$ Items not included in analysis due to low factor loading 


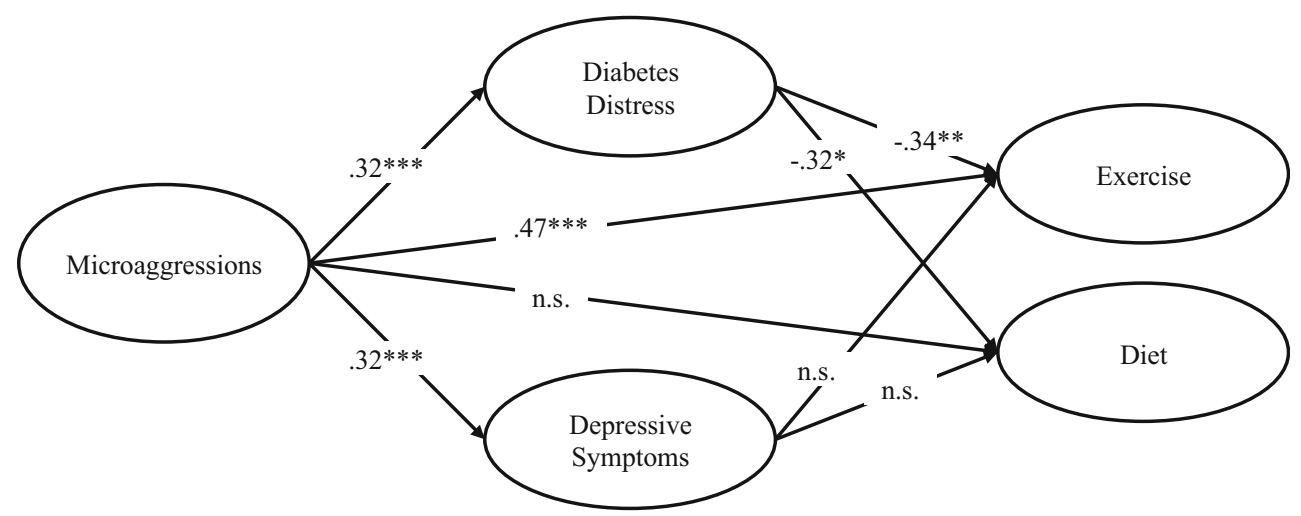

Fig. 1 Structural equation model of microaggressions, diabetes distress, depressive symptoms, and self-care behaviors. Note: Standardized coefficients. Controlling for gender, income, on/off reservation, and age (not shown). ${ }^{*} p<.05 ; * * p<.01 ; * * * p<.001$

$\$ 10,000$ ranges; the midpoints of these ranges were divided by the number of people living in the household. Reservation status was coded $1=$ on reservation, $0=$ off reservation. Age was a continuous indicator of age in years, ranging from 18 to 77 years.

\section{Results}

The final sample consisted of 194 participants, for a response rate of $67 \%$. The analytic sample for the current study was $99 \%$ of the original sample $(n=192)$, and was on average 46.28 years old and $55.2 \%$ female. The mean per capita family income was $\$ 9781$ and the median education level corresponded to "some college". Approximately $79 \%$ of the respondents lived on a reservation. Participants had received a diagnosis of diabetes on average 19 months prior to baseline data collection.

Structural equation modeling (SEM) was employed to test the hypotheses. All analyses were conducted using full information maximum likelihood with robust standard errors in MPlus 7 (Muthén \& Muthén, 2007). We first estimated a measurement model to determine whether the model provided a good fit to the data, consisting of all of the latent variables included, all correlated with each other. Items and factor loadings for all latent variables are provided in Table 1. Standard model fit indices and cut-off values were used to assess model fit: CFI greater than .90 but ideally greater than .94, and RMSEA less than .06. Two microaggressions items ( 1 and 5, Table 1$)$ were removed due to low factor loadings $(<.40)$. Removing those items resulted in acceptable model fit $\left(\chi^{2} 337.725 ; d f=243\right.$; CFI $=.928$; RMSEA $=.045)$. The structural model included directional paths between constructs and a correlation between the two self-care latent variables. All latent variables were regressed on three control variables (i.e., income, on-reservation location, age). Model fit was acceptable with control vari- ables $\quad$ added $\quad\left(\chi^{2} \quad 468.783 ; \quad d f=319 ; \quad\right.$ CFI $=.896$; RMSEA $=.049)$. The final model is displayed in Fig. 1 (demographic control variables not shown).

There were several significant associations between the focal and control variables. Gender was positively associated with both diabetes distress $(b=0.51,95 \%$ CI $0.23-0.79)$ and depressive symptoms $(b=0.42,95 \%$ CI $0.20-0.64)$. Income was negatively associated with diabetes distress $(b=-0.17,95 \% \mathrm{CI}-0.31$ to -0.04$)$ and depressive symptoms $(b=-0.21,95 \%$ CI -0.32 to $-0.11)$. Age was negatively associated with exercise ( $b=-0.17,95 \% \mathrm{CI}-0.31$ to -0.03 ), but positively associated with diet $(b=0.23,95 \%$ CI $0.07-0.37)$.

The first hypothesis, that microaggressions would be associated with more diabetes distress and fewer self-care behaviors, was partially supported (Table 2). Microaggressions were positively associated with diabetes distress $(b=0.32,95 \%$ CI $0.17-0.47)$. Contrary to the first hypothesis, microaggressions had a nonsignificant association with diet and was positively related to exercise ( $b=0.47,95 \%$ CI $0.30-0.63$ ). The second hypothesis, that diabetes distress would be negatively related to self-care behaviors, was supported. Diabetes distress was negatively associated with both the frequency of following a healthy $\operatorname{diet}(b=-0.32,95 \% \mathrm{CI}-0.55$ to -0.09$)$ and exercising $(b=-0.34,95 \% \mathrm{CI}-0.53$ to -0.15$)$.

We examined the decomposition of effects for the third hypothesis, that the association between microaggressions and self-care would operate indirectly via diabetes distress. The indirect path between diabetes distress and exercise was significant and negative $(b=-0.11,95 \% \mathrm{CI}-0.20$ to - 0.02), and the indirect relationship between microaggressions and diet was marginally significant and negative $(b=-0.10, p=.056,95 \% \mathrm{CI}-0.19$ to $-0.01)$. These results indicate that microaggressions were related to poorer adherence to exercise and a healthy diet via their relationship with diabetes distress. 
Table 2 Standardized regressions coefficients from the structural equation model $(n=192)$

\begin{tabular}{|c|c|c|c|c|c|c|}
\hline & \multicolumn{6}{|c|}{ Outcome variables } \\
\hline & \multicolumn{2}{|c|}{ Micro-aggressions } & \multicolumn{2}{|l|}{ Diabetes distress } & \multicolumn{2}{|c|}{ Depressive symptoms } \\
\hline & $\mathrm{b}$ & \multirow[t]{2}{*}{$95 \% \mathrm{CI}$} & $\mathrm{b}$ & $95 \% \mathrm{CI}$ & $\mathrm{b}$ & $95 \% \mathrm{CI}$ \\
\hline Microaggressions & & & $0.32 * *(0.09)$ & $0.17,0.47$ & $0.32 * * *(0.08)$ & $0.19,0.45$ \\
\hline \multicolumn{7}{|l|}{ Diabetes distress } \\
\hline \multicolumn{7}{|l|}{ Depressive symptoms } \\
\hline Gender $($ female $=1$ ) & $0.03(0.16)$ & $-0.30,0.24$ & $0.51 * *(0.17)$ & $0.23,0.79$ & $0.42 * *(0.14)$ & $0.20,0.64$ \\
\hline Income & $-0.02(0.09)$ & $-0.16,0.13$ & $-0.17 *(0.08)$ & $-0.31,-0.04$ & $-0.21 * *(0.06)$ & $-0.32,-0.11$ \\
\hline On/off reservation $($ on $=1)$ & $0.21(0.20)$ & $-0.13,0.54$ & $0.29(0.20)$ & $-0.03,0.62$ & $-0.36(0.19)$ & $-0.66,-0.06$ \\
\hline Age & $0.05(0.08)$ & $-0.08,0.19$ & $0.02(0.08)$ & $-0.11,0.15$ & $-0.07(0.08)$ & $-0.20,0.06$ \\
\hline \multirow[t]{4}{*}{$\mathrm{R}^{2}$} & \multicolumn{2}{|l|}{0.01} & 0.22 & \multicolumn{3}{|c|}{0.19} \\
\hline & \multicolumn{6}{|c|}{ Outcome variables } \\
\hline & \multicolumn{3}{|l|}{ Diet } & \multicolumn{3}{|c|}{ Exercise } \\
\hline & \multicolumn{2}{|l|}{$\mathrm{b}$} & $95 \% \mathrm{CI}$ & \multicolumn{2}{|l|}{$\mathrm{b}$} & $95 \% \mathrm{CI}$ \\
\hline Microaggressions & \multicolumn{2}{|c|}{$0.16(0.11)$} & $-0.02,0.35$ & \multicolumn{2}{|c|}{$0.47 * * *(0.10)$} & $0.30,0.63$ \\
\hline Diabetes distress & \multicolumn{2}{|c|}{$-0.32 *(0.14)$} & $-0.55,-0.09$ & \multicolumn{2}{|c|}{$-0.34 * *(0.11)$} & $-0.53,-0.15$ \\
\hline Depressive symptoms & \multicolumn{2}{|c|}{$-0.22(0.12)$} & $-0.42,-0.02$ & \multicolumn{2}{|c|}{$-0.07(0.11)$} & $-0.25,0.11$ \\
\hline Gender $($ female $=1$ ) & \multicolumn{2}{|c|}{$0.15(0.22)$} & $-0.20,0.51$ & \multicolumn{2}{|c|}{$0.00(0.19)$} & $-0.31,0.31$ \\
\hline Income & \multicolumn{2}{|c|}{$0.17(0.09)$} & $0.02,0.31$ & \multicolumn{2}{|c|}{$-0.09(0.09)$} & $-0.23,0.06$ \\
\hline On/off reservation $($ on $=1)$ & \multicolumn{2}{|c|}{$0.44(0.22)$} & $0.07,0.82$ & \multicolumn{2}{|c|}{$-0.31(0.24)$} & $-0.69,0.09$ \\
\hline Age & \multicolumn{2}{|c|}{$0.21 *(0.09)$} & $0.07,0.37$ & \multicolumn{2}{|c|}{$-0.17 *(0.09)$} & $-0.31,-0.03$ \\
\hline $\mathrm{R}^{2}$ & \multicolumn{2}{|c|}{0.27} & & \multicolumn{2}{|c|}{0.25} & \\
\hline
\end{tabular}

Standard errors in parentheses. Model Fit: $\chi^{2}=468.783$; df $=319$; CFI $=.896$; RMSEA $=.049$

$* * * p<.001 ; * * p<.01 ; * p<.05$

To determine whether the observed relationships between diabetes distress and microaggressions, exercise, and diet were due to more general depressive symptoms and not distress specific to living with diabetes, we included a measure of depressive symptoms in the model. Although microaggressions were positively associated with depressive symptoms $(b=0.32,95 \%$ CI $0.19-0.45)$, depressive symptoms were unrelated to both self-care behaviors. Further, there were no indirect associations between microaggressions and self-care via depressive symptoms.

\section{Discussion}

This research contributes to a small but growing literature that documents the damaging health effects of racial microaggressions, the bothersome, subtle, and pervasive everyday experiences with racism or racist insults. It also extends previous research by examining a specific form of stress and diabetes-related outcomes in a sample of AI people with type 2 diabetes, a population with the highest rate of diabetes in the United States (Blackwell et al., 2014). Not only do microaggressions increase the risk of developing diabetes for AIs (Jiang et al., 2008), they also are associated with worse health among those who are already living with the disease, as shown in the current study. Specifically, we found that microaggressions were associated with more diabetes distress, which in turn were associated with decreased frequency of eating a healthy diet and exercising. Although not tested here, microaggressions could impact diabetes distress by negatively affecting overall quality of life (Dawson et al., 2015) and psychological resources such as mastery and self-esteem (Williams et al., 2012). Our results suggest that diabetes distress is an intervening variable linking microaggressions to self-care, making it an important and potentially malleable risk factor for poor self-care.

The relationship between microaggressions and diabetes distress was significant even when accounting for depressive symptoms. Although microaggressions were associated with depressive symptoms, depressive symptoms were not associated with either of the self-care behaviors. Our findings support other studies that have found diabetes 
distress to be distinct from more general depression and more likely to be associated with diabetes-related outcomes (Fisher et al., 2010; Zagarins et al., 2012). Moreover, (Fisher et al., 2014) argue that much of the overlap between depression and diabetes health outcomes is likely due to diabetes-specific distress, which has important treatment implications.

These results align with those from prior non-AI studies on the negative relationship between diabetes distress and disease management, including self-care and medication adherence (Fisher et al., 2009; Gonzales et al., 2015), suggesting that the difficulties associated with diabetes distress are similar across groups. Our findings are also informative for diabetes prevention and treatment specific to AIs, and, to at least some extent, other minority groups. Reservationdwelling AIs occupy a marginalized position in American society, which can carry with it an abundance of stressors and a shortage of resources to buffer their harmful effects. Racial discrimination, which frequently accompanies marginalized statuses, contributes to greater disease burden; one way that it impacts the health of our sample of AI people with diabetes is through its association with diabetes distress. Although we did not examine other stressors, it is unlikely that discrimination operates in isolation from other sources of stress, and indeed may contribute to heightened stress reactivity (Brondolo et al., 2011). Furthermore, the uneven distribution of stressors may further exacerbate the distress of managing diabetes and undermine health behaviors. Increasing resources to ameliorate the harmful effects of microaggressions and diabetes distress is critical. This includes the resources needed to decrease exposure to stressors that adversely affect health and health behaviors (Pearlin et al., 2005) and bolster resources to manage stress.

We also found a positive relationship between microaggressions and exercise, which was contrary to our hypothesis. Exercise may be a way of coping with stress, including microaggressive experiences. It could also bring individuals into contact with non-AI people, such as at a gym or on a bicycle path, increasing the opportunity to encounter more microaggressions. Future research could untangle this unexpected relationship with longitudinal data and including additional stressors.

\section{Limitations}

The cross-sectional data used do not allow us to identify causal relationships. The small size of the sample is another limitation, particularly in the limited number of covariates that could be analyzed. Future research should examine a broader array of outcomes as well as additional mediating variables to expand our understanding of how microaggressions affect health for AIs with diabetes.

\section{Conclusions}

We examined the associations between microaggressive experiences and outcomes important to disease progression and treatment compliance (i.e., diabetes distress, diet, and exercise) in a sample of AI adults with type 2 diabetes. Microaggressions were associated with higher diabetes distress and negatively impact behaviors that are critical to managing it and reducing associated complications. Microaggressions, although distressing generally, may be even more consequential in health care settings and adversely impact health behaviors and help-seeking among AI patients (Gonzales et al., 2014; Walls et al., 2015). Healthcare providers must be vigilant in recognizing their biases and reducing their microaggressive words and actions. Additionally, clinicians wishing to improve selfcare should regularly assess the presence of diabetes distress in patients presenting with diabetes (Fisher et al., 2008). Mistaking diabetes distress for more general depression can lead to inappropriate treatment and little improvement in health (Fisher et al., 2014). Because the demands of diabetes care regimens can be very burdensome and thereby distressing, avenues for intervention include initiating conversations about and offering support for managing the emotional distress related to the disease (Gonzalez et al., 2011), as well as targeting perceived control over diabetes outcomes (Gonzales et al., 2015). It may not be possible to reduce patient exposure to stressors, but the amelioration of diabetes distress could improve self-care even in the presence of pervasive, chronic social stressors such as microaggressions.

Acknowledgements Research reported in this manuscript was supported by the National Institute on Diabetes, Digestive and Kidney Diseases \#DK091250 (M. Walls, PI). The content is solely the responsibility of the authors and does not necessarily represent the official views of the National Institutes of Health. The authors thank the project's community members: Sidnee Kellar, Rose Barber, Robert Miller, Tweed Shuman, Lorraine Smith, Sandy Zeznanski, Patty Subera, Tracy Martin, Geraldine Whiteman, Lisa Perry, Trisha Prentice, Alexis Mason, Charity Prentice-Pemberton, Kathy Dudley, Mona Nelson, Eileen Miller, Geraldine Brun, Murphy Thomas, Hope Williams, Betty Jo Graveen, Daniel Chapman, Jr., Mary SikoraPetersen, Tina Handeland, Phillip Chapman, Sr., GayeAnn Allen, Frances Whitfield, Doris Isham, Stan Day, Jane Villebrun, Beverly Steel, Muriel Deegan, Peggy Connor, Michael Connor, Ray E. Villebrun, Sr., Pam Hughes, Cindy McDougall, Melanie McMichael, Robert Thompson, Sandra Kier.

\section{Compliance with ethical standards}

Conflict of interest Kelley J. Sittner, Brenna L. Greenfield, and Melissa L. Walls declare that they have no conflicts of interest

Human and animal rights and Informed consent All procedures performed in studies involving human participants were in accordance with the ethical standards of the institutional and/or national research committee and with the 1964 Helsinki declaration and its 
later amendments or comparable ethical standards. Informed consent was obtained from all patients for being included in the study.

\section{References}

Aikens, J. E., \& Mayes, R. (1997). Elevated glycosylated albumin in NIDDM is a function of recent everyday environmental stress. Diabetes Care, 20(7), 1111-1113. https://doi.org/10.2337/ diacare.20.7.1111

Anderson, R. J., Freedland, K. E., Clouse, R. E., \& Lustman, P. J. (2001). The prevalence of comorbid depression in adults with diabetes: A meta-analysis. Diabetes Care, 24(6), 1069-1078. https://doi.org/10.2337/diacare.24.6.1069

Blackwell, D. L., Lucas, J. S., \& Clarke, T. C. (2014). Summary health statistics for U.S. adults: National health interview survey, 2012. Vital Health Statistics, 10(260), 1-161.

Brondolo, E., Love, E. E., Pencille, M., Schoenthaler, A., \& Ogedegbe, G. (2011). Racism and hypertension: A review of the empirical evidence and implications for clinical practice. American Journal of Hypertension, 24(5), 518-529. https://doi. org/10.1038/ajh.2011.9

Chae, D. H., \& Walters, K. L. (2009). Racial discrimination and racial identity attitudes in relation to self-rated health and physical pain and impairment among two-spirit American Indians/Alaska Natives. American Journal of Public Health, 99, S144-S151. https://doi.org/10.2105/AJPH.2007.126003

Dawson, A. Z., Walker, R. J., Campbell, J. A., \& Egede, L. E. (2015). Effect of perceived racial discrimination on self-care behaviors, glycemic control, and quality of life in adults with type 2 diabetes. Endocrine, 49(2), 422-428.

Dolezsar, C. M., McGrath, J. J., Herzig, A. J. M., \& Miller, S. B. (2014). Perceived racial discrimination and hypertension: A comprehensive systematic review. Health Psychology, 33(1), 20-34. https://doi.org/10.1037/a0033718

Fisher, L., Gonzalez, J. S., \& Polonsky, W. H. (2014). The confusing tale of depression and distress in patients with diabetes: A call for greater clarity and precision. Diabetic Medicine, 31(7), 764-772. https://doi.org/10.1111/dme.12428

Fisher, L., Hessler, D. M., Polonsky, W. H., \& Mullan, J. (2012). When is diabetes distress clinically meaningful? Establishing cut points for the Diabetes Distress Scale. Diabetes Care, 35(2), 259-264. https://doi.org/10.2337/dc11-1572

Fisher, L., Mullan, J. T., Arean, P., Glasgow, R. E., Hessler, D., \& Masharani, U. (2010). Diabetes distress but not clinical depression or depressive symptoms is associated with glycemic control in both cross-sectional and longitudinal analyses. Diabetes Care, 33(1), 23-28.

Fisher, L., Mullan, J. T., Skaff, M. M., Glasgow, R. E., Arean, P., \& Hessler, D. (2009). Predicting diabetes distress in patients with type 2 diabetes: A longitudinal study. Diabetic Medicine, 26(6), 622-627. https://doi.org/10.1111/j.1464-5491.2009.02730.x

Fisher, L., Skaff, M. M., Mullan, J. T., Arean, P., Glasgow, R., \& Masharani, U. (2008). A longitudinal study of affective and anxiety disorders, depressive affect and diabetes distress in adults with type 2 diabetes. Diabetic Medicine, 25(9), 1096-1101. https://doi.org/10.1111/j.1464-5491.2008.02533.x

Fisher, L., Skaff, M. M., Mullan, J. T., Arean, P., Mohr, D., Masharani, U., et al. (2007). Clinical depression versus distress among patients with Type 2 diabetes. Diabetes Care, 30(3), 542-548. https://doi.org/10.2337/dc06-1614

Gonzales, L., Davidoff, K. C., Nadal, K. L., \& Yanos, P. T. (2015). Microaggressions experienced by persons with mental illnesses: An exploratory study. Psychiatric Rehabilitation Journal, 38(3), 234. https://doi.org/10.1037/prj0000096
Gonzales, K. L., Lambert, W. E., Fu, R., Jacob, M., \& Harding, A. K. (2014). Perceived racial discrimination in health care, completion of standard diabetes services, and diabetes control among a sample of American Indian women. The Diabetes Educator, 40(6), 747-755. https://doi.org/10.1177/0145721714551422

Gonzalez, J. S., Fisher, L., \& Polonsky, W. H. (2011). Depression in diabetes: Have we been missing something important? Diabetes Care, 34(1), 236-239.

Indian Health Service. (2016). Indian Health Disparities. Rockville, MD: Indian Health Service. Retrieved from https://www.ihs.gov/ newsroom/factsheets/disparities/

Iwasaki, Y., Bartlett, J., \& O’Neil, J. (2005). Coping with stress among Aboriginal women and men with diabetes in Winnipeg, Canada. Social Science and Medicine, 60(5), 977-988. https:// doi.org/10.1016/j.socscimed.2004.06.032

Jiang, L., Beals, J., Whitesell, N. R., Roubideaux, Y., Manson, S. M., Team, A.-S., et al. (2008). Stress burden and diabetes in two American Indian reservation communities. Diabetes Care, 31(3), 427-429. https://doi.org/10.2337/dc07-2044

Kroenke, K., Spitzer, R. L., \& Williams, J. B. (2001). The PHQ-9. Journal of General Internal Medicine, 16(9), 606-613.

Lewis, T. T., Cogburn, C. D., \& Williams, D. R. (2015). Self-reported experiences of discrimination and health: Scientific advances, ongoing controversies, and emerging issues. Annual Review of Clinical Psychology, 11, 407-440. https://doi.org/10.1146/ annurev-clinpsy-032814-112728

McQuaid, R. J., Bombay, A., McInnis, O. A., Matheson, K., \& Anisman, H. (2015). Childhood adversity, perceived discrimination, and coping strategies in relation to depressive symptoms among First Nations adults in Canada: The moderating role of unsupportive social interactions from ingroup and outgroup members. Cultural Diversity and Ethnic Minority Psychology, 21(3), 326-336. https://doi.org/10.1037/a0037541

Muthén, L. K., \& Muthén, B. O. (2007). Mplus User's guide (5th ed.). Los Angeles: Muthen \& Muthen.

National Center for Health Statistics. (2016). Health, United States, 2015: With Special Feature on Racial and Ethnic Health Disparities. Hyattsville, MD: U.S. Department of Health and Human Services. Retrieved from http://www.cdc.gov/nchs/data/ hus/hus15.pdf\#specialfeature

Paradies, Y. (2006). A systematic review of empirical research on self-reported racism and health. International Journal of Epidemiology, 35(4), 888-901. https://doi.org/10.1093/ije/dy1056

Pascoe, E. A., \& Smart Richman, L. (2009). Perceived discrimination and health: A meta-analytic review. Psychological Bulletin, 135(4), 531-554. https://doi.org/10.1037/a0016059

Pearlin, L. I., Menaghan, E. G., Lieberman, M. A., \& Mullan, J. T. (1981). The stress process. Journal of Health and Social Behavior, 337-356.

Pearlin, L. I., Schieman, S., Fazio, E. M., \& Meersman, S. C. (2005). Stress, health, and the life course: Some conceptual perspectives. Journal of Health and Social Behavior, 46(2), 205-219. https:// doi.org/10.1177/002214650504600206

Schmitt, A., Reimer, A., Kulzer, B., Haak, T., Gahr, A., \& Hermanns, N. (2015). Negative association between depression and diabetes control only when accompanied by diabetes-specific distress. Journal of Behavioral Medicine, 38(3), 556-564. https://doi.org/ 10.1007/s10865-014-9604-3

Sue, D. W., Capodilupo, C. M., Torino, G. C., Bucceri, J. M., Holder, A., Nadal, K. L., et al. (2007). Racial microaggressions in everyday life: implications for clinical practice. American Psychologist, 62(4), 271. https://doi.org/10.1037/0003-066X.62. 4.271

Toobert, D. J., Hampson, S. E., \& Glasgow, R. E. (2000). The summary of diabetes self-care activities measure: Results from 7 studies and a revised scale. Diabetes Care, 23(7), 943-950. 
Turner, R. J., Wheaton, B., \& Lloyd, D. A. (1995). The epidemiology of social stress. American Sociological Review, 104-125.

Wagner, J. A., Tennen, H., Finan, P. H., Ghuman, N., \& Burg, M. M. (2013). Self-reported racial discrimination and endothelial reactivity to acute stress in women. Stress and Health, 29(3), 214-221. https://doi.org/10.1002/smi.2449

Walls, M. L., Chapple, C. L., \& Johnson, K. D. (2007). Strain, emotion, and suicide among American Indian youth. Deviant Behavior, 28(3), 219-246. https://doi.org/10.1080/ 01639620701233100

Walls, M. L., Gonzalez, J., Gladney, T., \& Onello, E. (2015). Unconscious biases: Racial microaggressions in American Indian health care. The Journal of the American Board of Family Medicine, 28(2), 231-239. https://doi.org/10.3122/jabfm. 2015.02.140194

Walters, K. L., \& Simoni, J. M. (2002). Reconceptualizing Native women's health: An "indigenist" stress-coping model. American
Journal of Public Health, 92(4), 520-524. https://doi.org/10. 2105/AJPH.92.4.520

Williams, D. R., Haile, R., Mohammed, S. A., Herman, A., Sonnega, J., Jackson, J. S., et al. (2012). Perceived discrimination and psychological well-being in the USA and South Africa. Ethnicity and Health, 17(1-2), 111-133.

Williams, D. R., \& Mohammed, S. A. (2009). Discrimination and racial disparities in health: Evidence and needed research. Journal of Behavioral Medicine, 32(1), 20-47. https://doi.org/10. 1007/s10865-008-9185-0

Zagarins, S. E., Allen, N. A., Garb, J. L., \& Welch, G. (2012). Improvement in glycemic control following a diabetes education intervention is associated with change in diabetes distress but not change in depressive symptoms. Journal of Behavioral Medicine, 35(3), 299-304. https://doi.org/10.1007/s10865-011-9359-z 